\title{
Stability and Countermeasures for a Deposit Slope with Artificial Scarp: Numerical Analysis and Field Monitoring
}

\author{
Yong Hong, ${ }^{1}$ Zhushan Shao $\mathbb{D}^{1},{ }^{1}$ Guangbin Shi, ${ }^{1}$ and Jiabao Liu ${ }^{2}$ \\ ${ }^{1} X i$ 'an University of Architecture and Technology, Xi'an 710055, China \\ ${ }^{2}$ The1st Engineering Co., Ltd. of China Railway 12th Bureau Group, Xi'an 710038, China \\ Correspondence should be addressed to Zhushan Shao; shaozhushan@xauat.edu.cn
}

Received 7 June 2020; Revised 14 October 2020; Accepted 14 December 2020; Published 28 December 2020

Academic Editor: Nuwen Xu

Copyright (c) 2020 Yong Hong et al. This is an open access article distributed under the Creative Commons Attribution License, which permits unrestricted use, distribution, and reproduction in any medium, provided the original work is properly cited.

\begin{abstract}
This paper presents the results of the stability analysis of a deposit slope with an artificial scarp in a tunnel exit and an evaluation of the effectiveness of four proposed reinforcement schemes. A typical slope section was used to study the deposit slope stability and retaining mechanisms of the reinforcement systems. A series of two-dimensional (2D) finite element models (FEM), combined with a strength reduction technique, was established using the Phase ${ }^{2}$ software. According to field monitoring results, the horizontal displacements of the front, middle, and rear of the slope decreased gradually, and the safety factor increased successively. The front of the deposit slope was in a state of limit equilibrium as a result of the artificial scarp formed by long-term manual excavation. Anchors and concrete frame beams provided stress compensation and improve the stability of the deposit slope, and front prestressed anchor cables and stability piles strengthened the mechanical properties of the rock and soil masses and provided resistance at the front of the deposit. Rear stability piles prevented the front of the deposit from being pushed and the middle and rear of the deposit from being pulled and provided resistance at the front of the deposit. The field monitoring also showed that the deformation of the deposit slope was effectively controlled. The study results provide insights into the effectiveness of measures for reinforcing and maintaining the stability of deposit slope with artificial scarps.
\end{abstract}

\section{Introduction}

Over the past few years, transportation facilities (e.g., railroads and highways) have increasingly been extended into mountainous and hilly areas in conjunction with rapid economic and social development [1-5]. During tunnelling in such areas, rock engineers normally encounter the problem of slope stability. Statistics data shows that there are up to 148 landslides and rockfalls along the Sichuan-Tibet railway [6], and along the Dujiangyan City to Siguniang Mountain railway the stability of 32 tunnel slopes needs to be measured and evaluated [7]. Slope instabilities have threatened the safety of tunnel portals. Slope failures cause not only economic losses but also the losses of human life $[8,9]$. Therefore, stability assessment and reinforcement on slope in mountainous regions are the premise for tunnel construction and operation [10].

The analysis of slope stability is a difficult task that involves the evaluation of a large number of factors, including geology, topography, slope materials, engineering activities, and rainfall [11]. In addition, a complete analysis, including geological and geomorphological fieldwork, field monitoring, and numerical modelling, is a necessary step for slope stability assessment [8]. Thus, this analysis and assessment of slope stability are crucial to the safe design and implementation of mitigation measures. Currently, slope stability can be analyzed by the limit equilibrium method, numerical methods [12, 13], and experimental methods [14]. Numerical methods, which have been widely applied to slope stability analyses, have significantly improved the speed and accuracy of slope stability analysis. In addition, the strength reduction method has gradually become a focus of theoretical research [15-17]. Various reinforcing measures (e.g., descending slopes, drainage, plugging cracks, piles, and rock bolts) have been applied to slope stabilization [18]. Stability piles and anchor frame beams are typical reinforcing measures used for large-scale slope engineering. Many 
researchers have studied the reinforcement mechanisms and reinforcement parameters of individual reinforcement countermeasures [19-21]. However, given the complexity of geological conditions, environmental factors, geotechnical parameters, and other factors involved in slope engineering, especially large-scale slope engineering, comprehensive reinforcement countermeasures are becoming more commonly applied. Comprehensive reinforcement mechanisms and optimization of reinforcement parameters related to slope stability await further study. In recent decades, much deposit slope engineering had been constructed [22-24]. The deposit slope is a kind of mechanical medium with complex characteristics such as discontinuity, heterogeneity, and anisotropy, which is different from common rock slope and soil slope [23]. In view of the complexity of the deposit slope problem, there is still a long way to study and solve practical engineering problems.

This case study focused on evaluating how an artificial scarp can influence the stability of a deposit slope and on evaluating the effectiveness of the four proposed reinforcement schemes. A two-dimensional (2D) finite element model was developed and combined with a shear strength analysis technique to analyze a typical deposit slope section to obtain insight into the pile-anchor-soil interaction mechanism and its contribution to deposit slope stability. The analysis was conducted using the Phase ${ }^{2}$ software. The movement of the deposit slope was monitored during construction, and the field measurements were compared to the numerical analysis results. Using a comparison analysis, we were able to perform a comprehensive evaluation of risks associated with the Taihedong tunnel deposit slope with an artificial scarp. Furthermore, we performed a reinforcement system design to ensure the safety of tunnel slope construction and operation.

\section{Geological Conditions}

2.1. General Description. The Taihedong tunnel, which is located in the northern Qingxin district of the city of Qingyuan in Guangdong Province, China, is a six-lane divided expressway tunnel (Figure 1). A scarp formed by manual excavation is above the tunnel exit. The scarp is $220 \mathrm{~m}$ long and 25 to $40 \mathrm{~m}$ high, and its slope ranges from 40 to $70^{\circ}$. The front edge of the scarp is a broad area formed by manual excavation. The right tunnel is inside the scarp, and the left tunnel is at the edge of the scarp. The supporting capacity has been seriously weakened by manual excavation at the toe of the deposit slope. The stability of the deposit slope has also diminished as deformation of the slope has occurred and tension cracks have formed as a result of excavation of the toe of the deposit.

The slope materials at the tunnel exit are mainly composed of Quaternary deposits. A slope stability analysis of the tunnel exit and reinforcement of the unstable sliding mass are needed to assess the effects of surface water, underground water, and human engineering activities $[25,26]$ and ensure slope safety.

The potentially unstable geological body at the tunnel exit is a colluvial deposit with multilayer and multistage characteristics. This deposit can be divided into three subdomains: the existing deformation area (Zone I), a potential deformation area (Zone II), and a paleo deposit area (Zone III). The volume of the deposit is approximately 2.5 million $\mathrm{m}^{3}$ (including 0.55 million $\mathrm{m}^{3}$ in Zone $\mathrm{I}$ ). The results of a geological survey indicate that there are eight tension cracks in the existing deformation area (Zone I). These cracks are typically $40-70 \mathrm{~m}$ long and $20-50 \mathrm{~cm}$ wide, with a maximum width of nearly $1 \mathrm{~m}$. The tunnel exit is located at the front of Zone I. Reinforcement was necessary to limit the deformation of the deposit slope before the tunnel excavation.

2.2. Ground Conditions. Borehole exploration and ultrahigh-density resistivity testing were performed to determine the deposit profiles, and soil samples were collected for laboratory tests. Figure 2 shows a representative cross section of the study site, based on the boring tests. The deposit slope is composed of four layers: from top to bottom, gravel soil, silty clay, fully weathered argillaceous siltstone, and strongly weathered argillaceous siltstone. The parent rock of the gravel soil is mainly strongly and moderately weathered argillaceous siltstone. Gravel, silty soil, and silty clay are interspersed with the gravel soil. The parent rock of the silty clay, which was formed by weathering of argillaceous siltstone after colluvium, is mainly strongly and moderately argillaceous siltstone. Fully weathered argillaceous siltstone had completely weathered into hard and plastic silty clay. The original structure of fully weathered argillaceous siltstone, which only retained the appearance of the original rock, was completely destroyed. The strongly weathered argillaceous siltstone, with an argillaceous silty structure, massive structural deterioration, and crack development, was broken, soft, and crushable by hand. The soil and rock properties determined from the site investigation and associated laboratory tests are summarized in Table 1.

2.3. Potential Sliding Plane. The various types of relevant strata at the study site exhibit significant differences in their engineering geological properties and permeability. To better guide the layout of the slope reinforcement system, the results of in situ tests (boring tests, geological surveying and mapping, and ultra-high-density resistivity surveying) were analyzed to estimate the potential slip surface of the deposit slope. Weak contact surface layers have developed in the following ways between the different soil and rock layers and could be potential sliding planes. (1) A weak contact surface layer has developed between layers of silty clay and fully weathered argillaceous siltstone. The gravel soil layer of the colluvial deposit is a permeable stratum. Consequently, relatively impermeable silty clay and fully weathered argillaceous siltstone have been infiltrated by rainwater. A weak layer has formed between them. (2) A weak contact surface layer has formed between fully weathered argillaceous siltstone and strongly weathered argillaceous siltstone. Shallow landslides and surface cracks have caused rainwater infiltration. A deep sliding surface has formed between the fully weathered argillaceous siltstone and the strongly weathered argillaceous siltstone, as confirmed by the results 


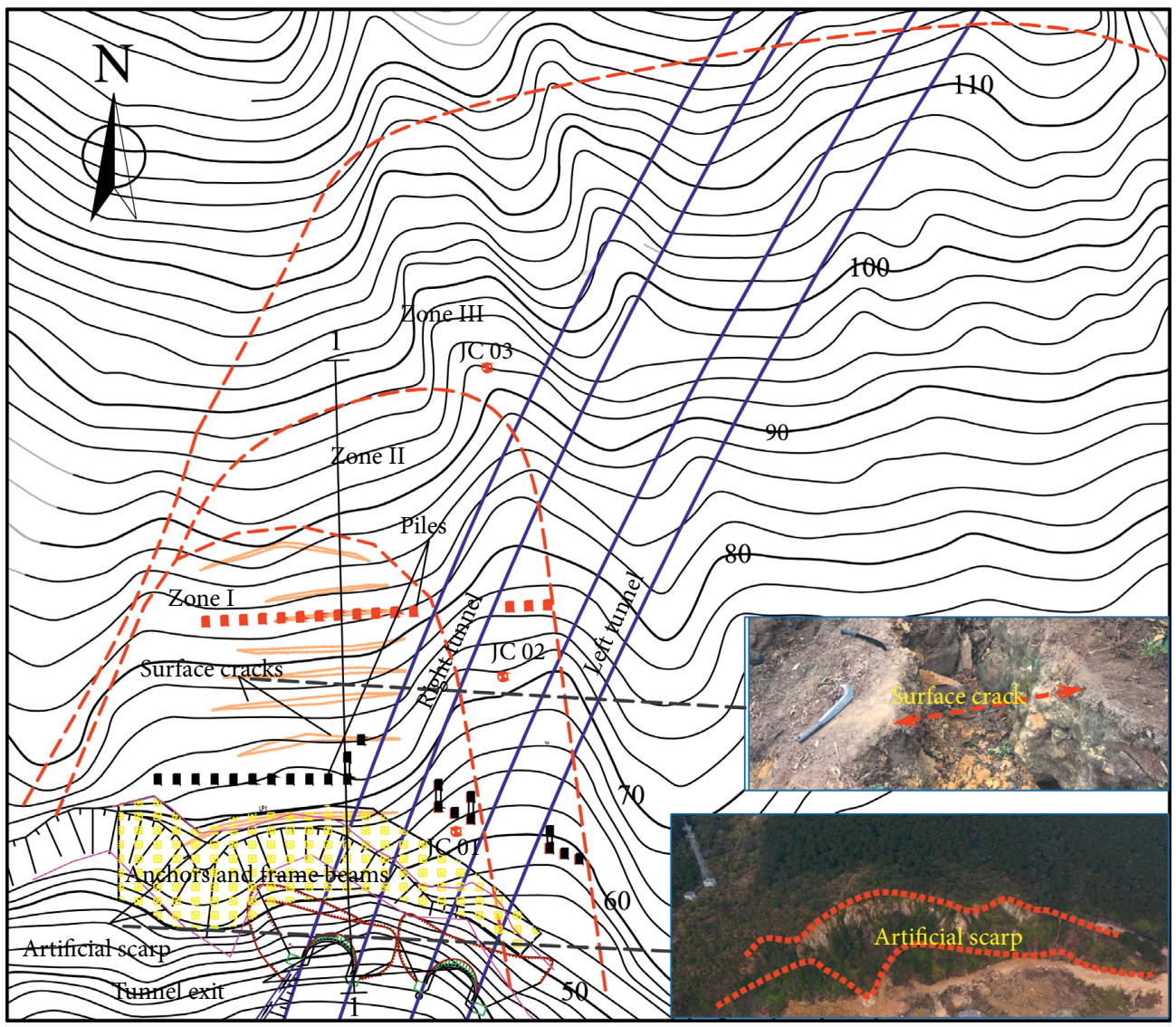

Figure 1: Layout of the tunnel and deposit slope.

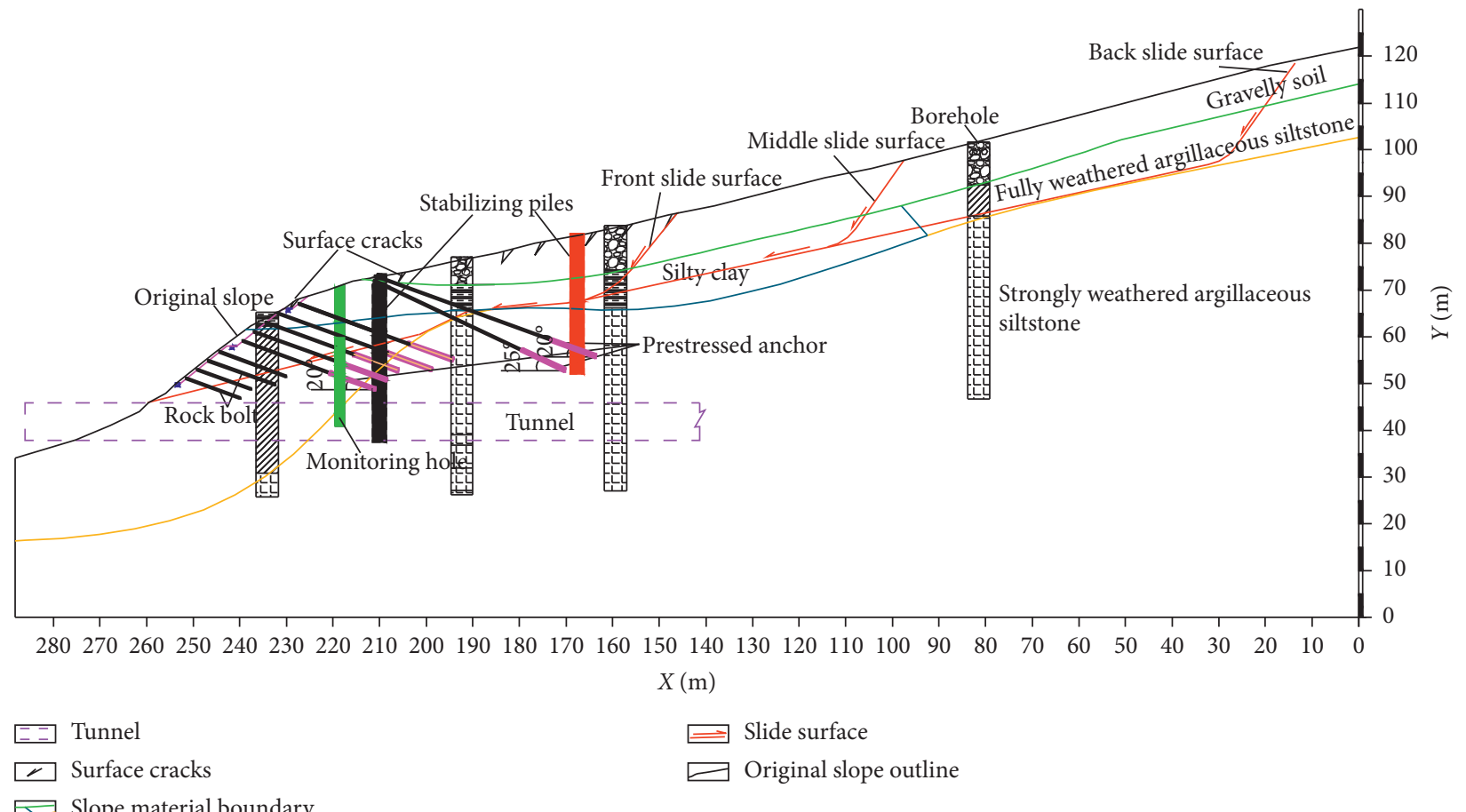

FIGURE 2: Representative geological profile along cross section 1-1 and the designed reinforcement system. 
TABLe 1: Soil and rock properties.

\begin{tabular}{|c|c|c|c|c|c|}
\hline Stratum & $\begin{array}{l}\text { Total unit weight } \\
\left(\mathrm{kN} / \mathrm{m}^{3}\right)\end{array}$ & Friction angle $\left({ }^{\circ}\right)$ & Cohesion $(\mathrm{kPa})$ & Young's modulus (MPa) & Poisson's ratio \\
\hline Gravel soil & 20 & 18 & 8 & 35 & 0.13 \\
\hline Silty clay & 19 & 12.5 & 15 & 25 & 0.25 \\
\hline Fully weathered argillaceous siltstone & 20 & 15 & 17 & 32 & 0.30 \\
\hline $\begin{array}{l}\text { Strongly weathered argillaceous } \\
\text { siltstone }\end{array}$ & 21 & 20 & 25 & 40 & 0.24 \\
\hline
\end{tabular}

of the boring tests and the ultra-high-density resistivity survey.

On the basis of a comprehensive consideration of the structural conditions and activity characteristics of the deposit slope, sliding surfaces can be divided into existing sliding surfaces and potential sliding surface. The deposit slope can be divided into front, middle, and rear three-stage sliding surfaces. The leading edge of these is located at the toe of the deposit slope (Figures 1 and 2).

\section{Numerical Simulation Method}

3.1. Computer Program for Numerical Analysis. A 2D plane strain numerical model was developed to analyze the slope stability based on the actual geological conditions at cross section 1-1, using the Phase ${ }^{2}$ software (version 8.0). One of the major features of Phase $^{2}$ is finite element slope stability analysis using the shear strength reduction (SSR) method. The model was developed on the basis of the mechanical properties of the soil and rock in each stratum summarized in Table 1.

Two-dimensional six-node triangular plane strain elements were used to discretize the 1-1 profile section of the deposit slope. The deposit model was uniformly meshed, with 2,183 elements connected with 4,496 nodes. All of the elements were found to be of good quality, on the basis of several trial-and-error tests. The number of bad elements was zero [27-29]. The boundary conditions of the slope model were set to constrain movement in both the $x$ and $y$ directions on the lateral sides and at the base of the slope, whereas the upper slope surface was unconstrained (Figure 3). Only gravity loading was applied to the model. The ratio of the horizontal to vertical stress was maintained at 1.0 [30]. The shear strength reduction (SSR) approach, with a tolerance of 0.001 , was used to determine the critical strength reduction factor (SRF) [31, 32]. This approach involves the determination of the SRF or the factor of safety (SOF) by successive reduction of the cohesion $(c)$ and internal friction angle $(\varphi)$ of the soil until failure occurs.

An iterative nonconvergence failure criterion was used to determine the critical SRF [33]. The deposit slope material was considered to be an elastic and perfectly plastic substance obeying a Mohr-Coulomb failure criterion. This was controlled by keeping the peak values equal to the residual values $[27,34]$.

The discrete stability piles and concrete frame beams were modeled as standard linear beams with flexural rigidity [35]. The prestressed anchors were modeled as tiebacks. The anchors were modeled as fully bonded. Figure 3 illustrates the finite element model established. The properties of the structural elements are summarized in Table 2.

3.2. Stability Analysis of Original Slope. The critical SRF and displacements for natural slope debris are shown in Figure 4. The numerical simulation results show that critical SRF values of $1.015,1.017$, and 1.029 and maximum displacements of $425 \mathrm{~mm}, 510 \mathrm{~mm}$, and $855 \mathrm{~mm}$ were obtained for the front, middle, and rear of the deposit slope, respectively, along the 1-1 profile section. The stability analysis of the middle of the deposit slope included consideration of the front of the deposit slope. The stability analysis of the rear of the deposit slope included consideration of the front and middle of the deposit slope. The results indicate that the deposit slope is in a state of limit equilibrium. The results show very good agreement with the field measurements. The deformation area is located above the artificial scarp and the tunnel exit, at the front edge of the deformation of the deposit slope. The factors of safety for the middle and rear of the deposit slope are considerably larger than that for the front of the deposit slope. Thus, the front of the deposit slope must be reinforced before excavation.

\section{Deposit Slope Reinforcement System and Analysis}

4.1. Slope Reinforcement Schemes. To analyze the global stability of the deposit slope with and without a reinforcement system and to further study the effects of different reinforcement schemes, four reinforcement schemes were considered: (A) front prestressed anchor cables and stability piles; (B) front prestressed anchor cables and stability piles and rear stability piles; (C) front prestressed anchor cables and stability piles, anchors, and concrete frame beams; and (D) front prestressed anchor cables and stability piles, rear stability piles, and anchors and concrete frame beams (as adopted in engineering practice). These four schemes are summarized in Table 3 . The symbol " $x$ " indicates a type of reinforcement that was not included in the reinforcement system.

The critical SRF values (Table 4) and displacements for the deposit slope for the four different reinforcement schemes are shown in Figure 5. The results indicate that the SRF values are the lowest for the front of the deposit slope and the highest for the rear of the deposit slope for all four reinforcement cases, A, B, C, and D. These results were found to be in good agreement with the measured results. Figure 5 shows that the slope stability levels associated with schemes A and B were not significantly different. Similar 


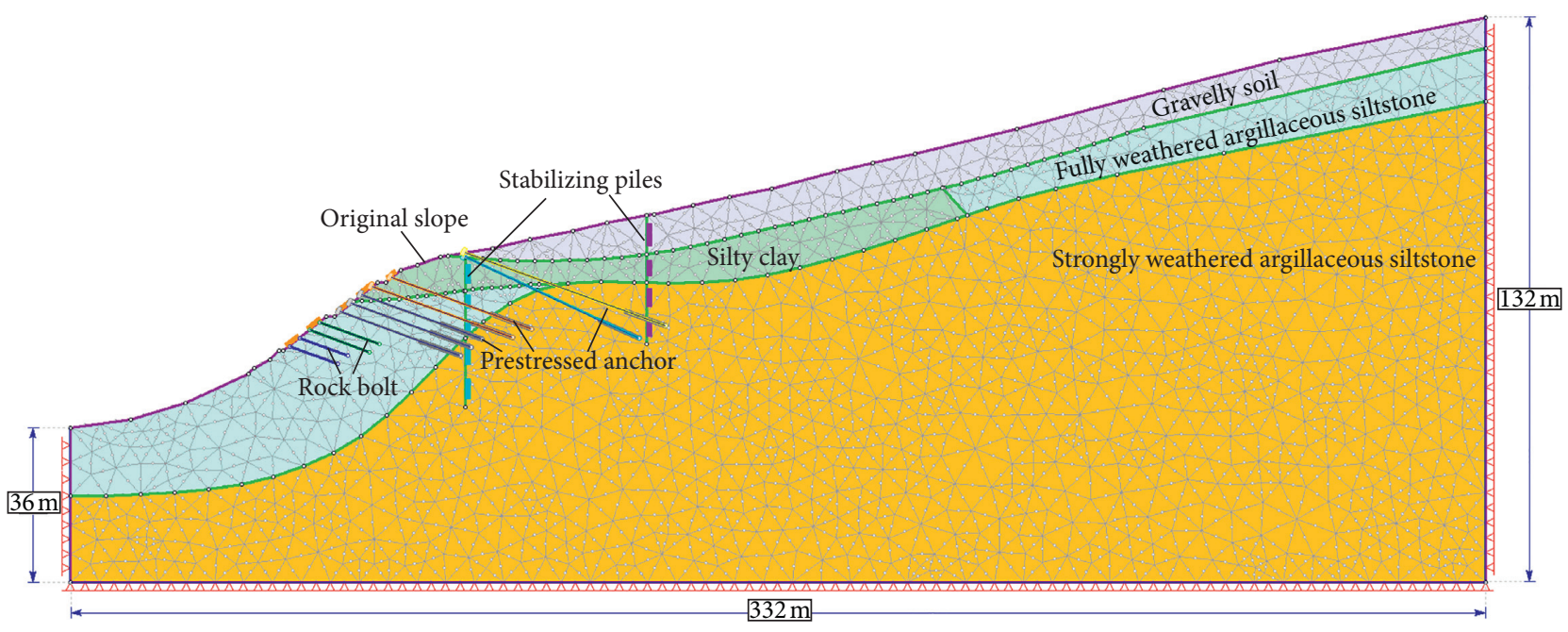

FIGURE 3: Finite element model for section 1-1.

Table 2: Properties of structural elements adopted in the finite element model.

\begin{tabular}{lcccc}
\hline \multirow{2}{*}{ Prestressed anchors } & Parameter & Bolt modulus & Tensile capacity & Pretensioning force \\
& Value & $19.5 \times 10^{4} \mathrm{MPa}$ & $1041 \mathrm{kN} / 1562 \mathrm{kN}$ & $183 \mathrm{kN} / 20 \mathrm{kN}$ \\
\hline \multirow{2}{*}{ Rock bolts } & Parameter & Bolt modulus & Tensile capacity & Residual tensile capacity \\
& Value & $20 \times 10^{4} \mathrm{MPa}$ & $220 \mathrm{kN}$ & $123 \mathrm{kN}$ \\
\hline \multirow{2}{*}{ Concrete frame beams/stabilizing piles } & Parameter & Young's modulus & Poisson's ratio & Properties \\
& Value & $3.0 \times 10^{4} \mathrm{MPa}$ & 0.2 & Elastic \\
\hline
\end{tabular}

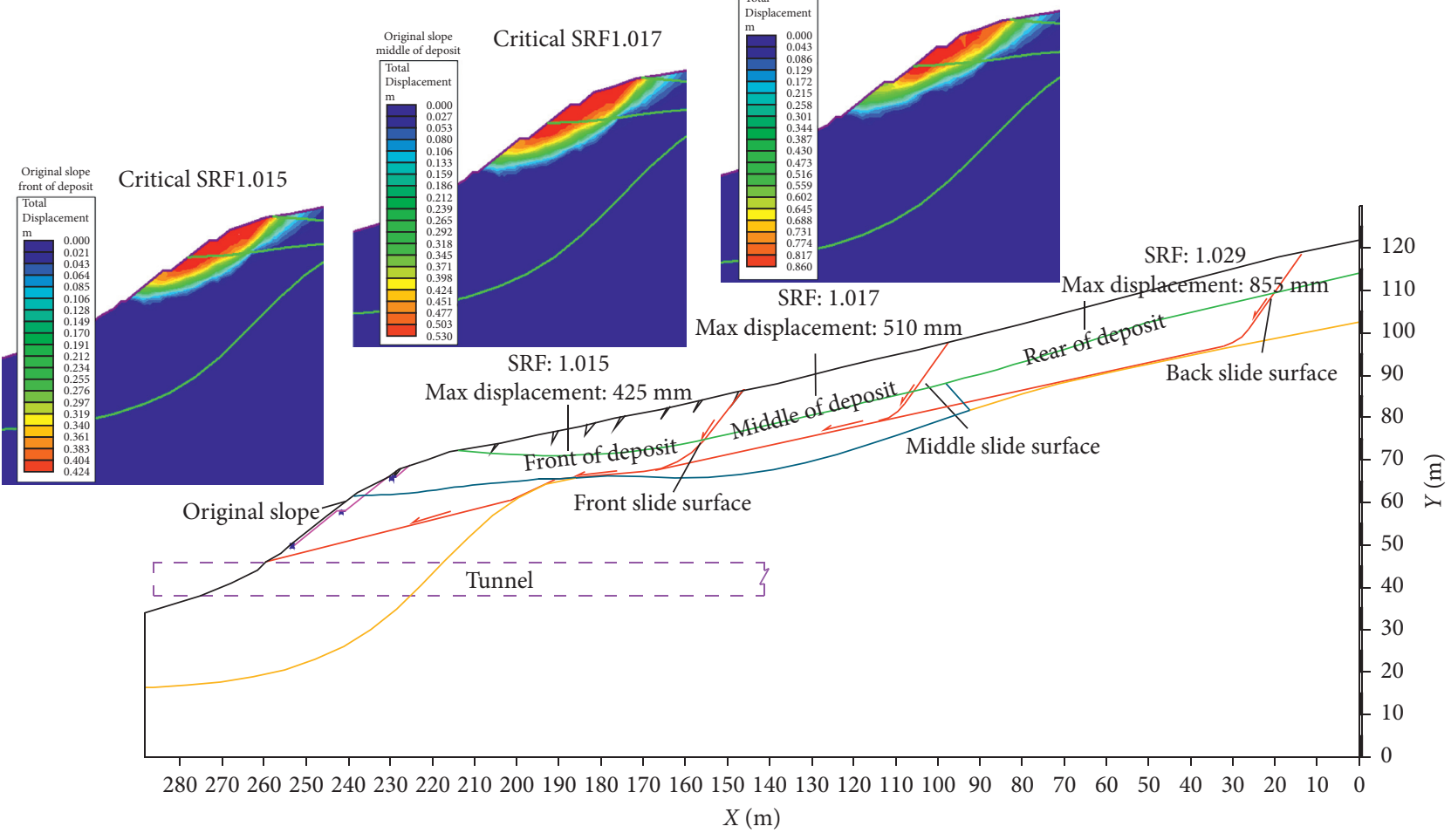

FIGURE 4: SSR analysis results for 1-1 profile section of natural deposit slope. 
TABLE 3: Reinforcement schemes.

\begin{tabular}{lccc}
\hline Scheme & Front prestressed anchor cables and stability piles & Rear stability piles & Anchors and concrete frame beams \\
\hline O & $\times$ & $\times$ & $\times$ \\
A & $\sqrt{ }$ & $\times$ & $\times$ \\
B & $\sqrt{ }$ & $\sqrt{ }$ & $\times$ \\
C & $\sqrt{ }$ & $\times$ & $\sqrt{ }$ \\
D & $\sqrt{ }$ & $\sqrt{ }$ & $\sqrt{ }$ \\
\hline
\end{tabular}

TABLE 4: Critical strength reduction factor (SRF) of reinforcement schemes.

\begin{tabular}{lccc}
\hline Deposit slope & \multicolumn{3}{c}{ SRF } \\
& Front & Middle & Rear \\
\hline Scheme O (unreinforced) & 1.015 & 1.017 & 1.029 \\
Scheme A & 1.045 & 1.047 & 1.049 \\
Scheme B & 1.047 & 1.050 & 1.055 \\
Scheme C & 1.422 & 1.432 & 1.459 \\
Scheme D & 1.428 & 1.440 & 1.515 \\
\hline
\end{tabular}

results were obtained for schemes $C$ and $D$. The reinforcement schemes differ primarily in whether the rear stability of the pile is considered. Schemes A and B were selected to analyze the function of stability piles and their influence on slope stability. Critical SRF values of 1.045 and 1.047 were obtained for schemes A and B, respectively. It appears that rear stability piles can effectively prevent the continued expansion of surface cracks, restrict deformation of the middle and rear of the deposit slope, and prevent the front soil from being pushed.

Critical SRF values of 1.045 and 1.015 were obtained for schemes A and O, respectively. The safety factor for scheme A was 3.0\% higher than that for scheme O. This result shows that the front stability piles provided resistance to deformation of the soil at the front of the deposit. The prestressed anchor cables improved the mechanical properties of the rock and soil. The front of the deposit was reinforced by the prestressed anchor cables and stability piles, and its stability was improved.

Critical SRF values of 1.422 and 1.045 were obtained for schemes $\mathrm{C}$ and $\mathrm{A}$. The safety factor for scheme $\mathrm{C}$ was $36.1 \%$ higher than that for scheme A and $40.1 \%$ higher than that for scheme O. As discussed previously, the deformation area was located at the front edge of the deformation body of the deposit slope. The anchors and concrete frame beams provided stress compensation for the artificial scarp and restricted the upper soil from continuing to be pulled. Thus, the analysis shows that the anchors and concrete frame beams significantly improved the stability of the deposit slope.

The front prestressed anchor cables and stability piles, the rear stability piles, and the anchors and concrete frame beams displayed different degrees of reinforcement effectiveness in the slope reinforcement system. Figure 6 and Table 4 show the numerical analysis results for the four different reinforcement schemes (Table 3). For scheme D, critical SRF values of $1.428,1.440$, and 1.515 were obtained for the front, middle, and rear of the deposit slope, respectively. These factors of safety are consistent with the GB
50330-2013 standard, which specifies a value of more than 1.30 for a grade III slope. Scheme D was therefore adopted for this engineering application.

4.2. Slope Reinforcement System. The deposit slope reinforcement systems were constructed before excavation to ensure the safe construction and operation of the Taihedong tunnel, including stabilization of piles, anchors, and concrete frame beams and establishment of groundwater drainage using collector wells. Figure 1 shows a plan view of the deposit slope reinforcement systems. Figure 2 shows a typical slope cross section used in this study.

Two rows of stabilizing piles were constructed as a primary slope reinforcement. These were buried piles with a cross section of $2.0 \times 3.0 \mathrm{~m}^{2}$. The front stability piles, ranging in length from 15 to $25 \mathrm{~m}$, were located approximately 4.9-12.3 $\mathrm{m}$ from the top of the scarp and were tied back by two prestressed anchor cables. The prestressed anchor cables were $45 \mathrm{~m}$ and $50 \mathrm{~m}$ in length and consisted of stranded wire cable. The prestressed anchor cables were installed at orientations of $20^{\circ}$ to $25^{\circ}$ downward, with a bond length of $10 \mathrm{~m}$. A total of 13 stability piles were installed to the right of the right tunnel at a spacing of $6 \mathrm{~m}$. A total of five stability piles were installed between the right tunnel and the left tunnel at a spacing of $5.5 \mathrm{~m}$. A total of four stability piles were installed to the left of the left tunnel at a spacing of $5.5 \mathrm{~m}$. The spacing between stability piles was $5 \mathrm{~m}$ near the tunnel.

The rear stability piles, which were $30 \mathrm{~m}$ long and spaced $6 \mathrm{~m}$ apart, were located at elevations of 82 to $84 \mathrm{~m}$ and were $50 \mathrm{~m}$ away from the front stability piles. Anchors and concrete frame beams were the other primary slope reinforcement measures. The rock bolts consisted of $40 \mathrm{~mm}$ diameter deformed steel bars, 12 and $15 \mathrm{~m}$ long, spaced $3 \mathrm{~m}$ apart. The prestressed anchor cables were stranded wire cables with lengths of 30 and $35 \mathrm{~m}$. The prestressed anchor cables were installed at an orientation of $20^{\circ}$ downward with a bond length of $10 \mathrm{~m}$. Figure 7 shows the sequence of the completed reinforcement works.

4.3. Field Measurement. To observe the behavior of the deposit slope during the installation of the stability piles, anchors, and cable frame beams, three displacement monitoring holes were established, designed to monitor the deflections of the deformation body. Figures 1 and 2 show plane and cross-sectional plan views, respectively, of the displacement monitoring holes. The purposes of monitoring hole JC01, which was located ahead of the front stability pile, were to determine the deformation characteristics of the 

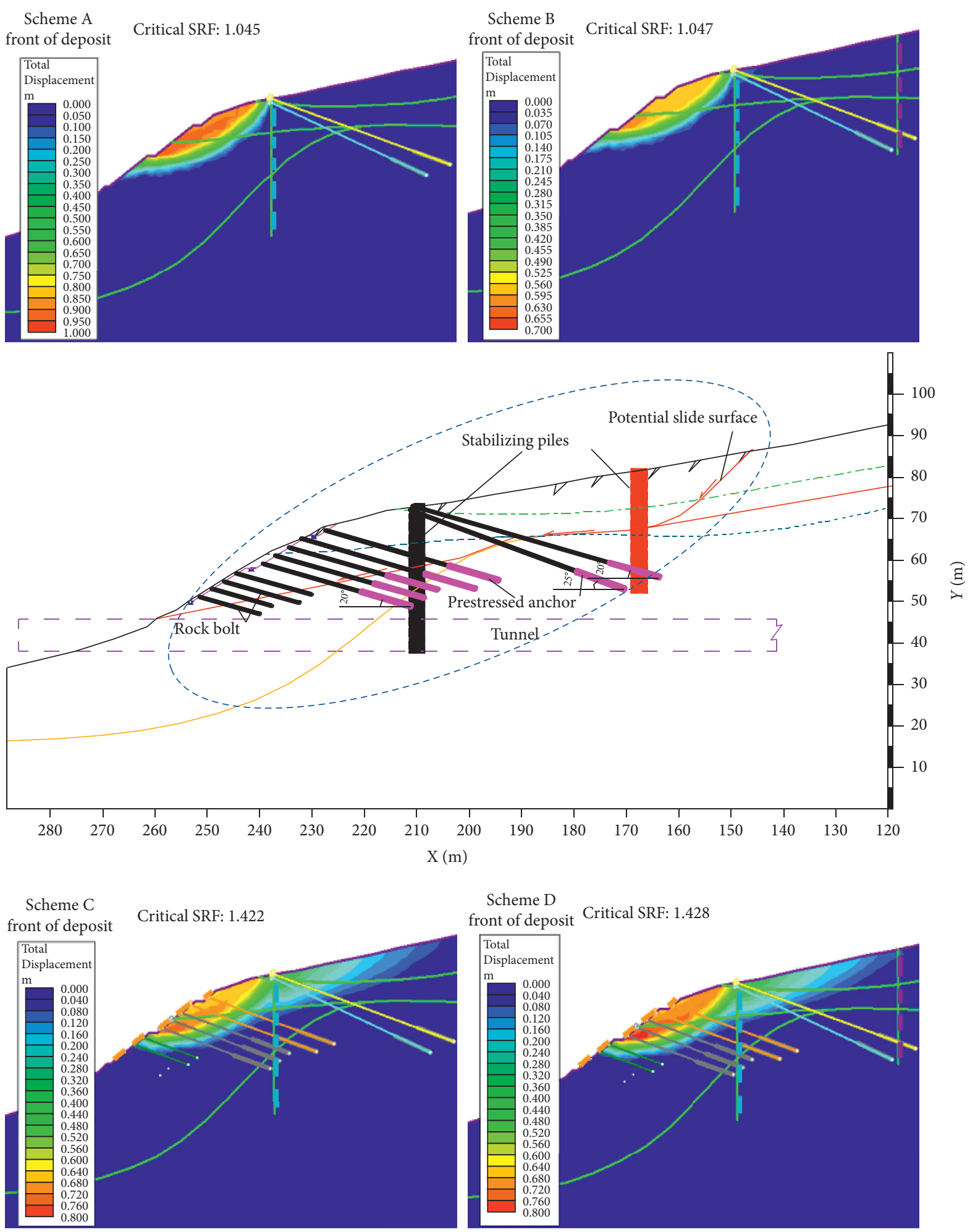

FIGURE 5: SSR analysis results for 1-1 profile section of deposit slope for different reinforcement schemes.

front slope and to forecast and warn geological disasters that may be caused by the construction of the slope reinforcement and tunnel excavation. The purpose of monitoring hole JC02, which was located between two rows of stability piles and between the left and right tunnel, was to monitor the potential sliding surface and the deformation of the deep sliding surface. The purpose of monitoring hole JC03, which was located outside the boundary of the deformation body, was to monitor the deformation of the back edge of the deposit slope. Sliding borehole inclinometers were installed to measure the deflections of the deformation body. Figure 8 shows the instrumentation system and photograph of the in 


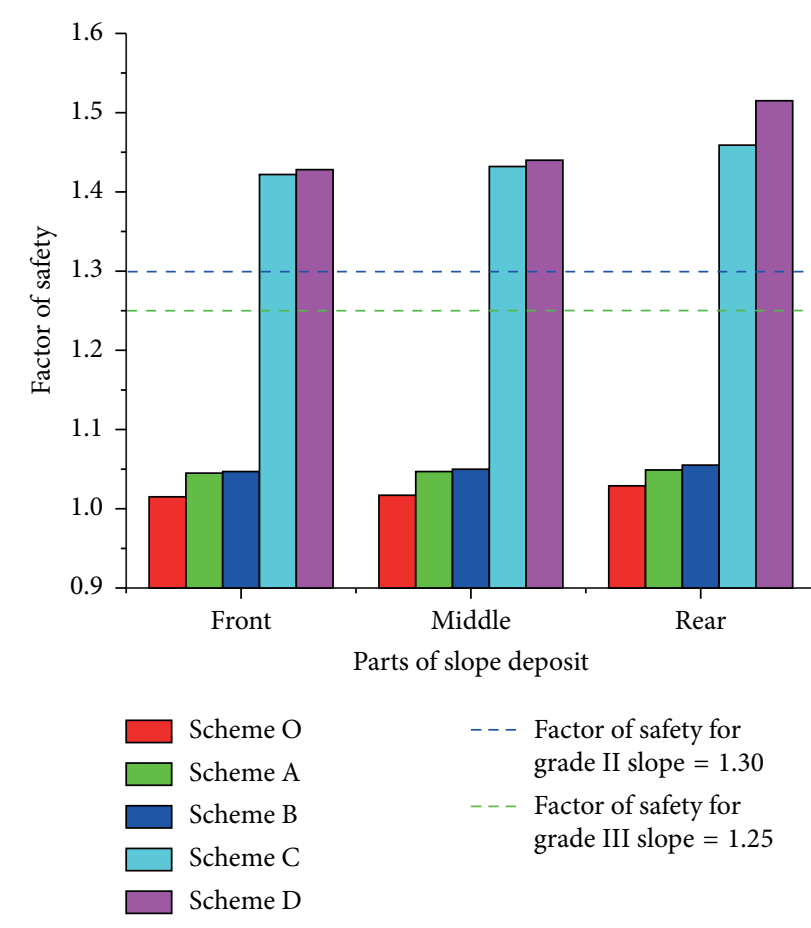

Figure 6: Changes in the FOS of the deposit slope for different reinforcement systems.

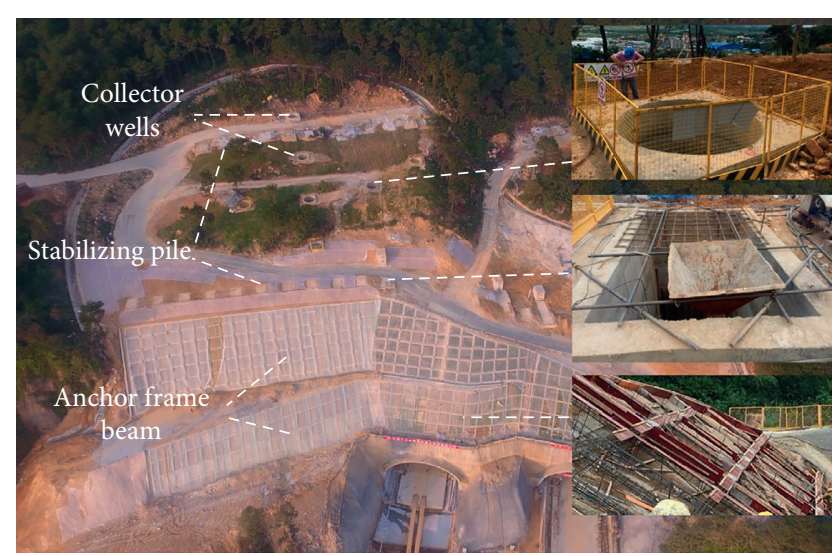

FIGURE 7: Deposit slope after stabilization work completed.

situ monitoring. An inspection of the deposit surface was also carried out.

The deformation of the deposit slope was analyzed based on the monitoring hole arrangement and the monitoring data collected. Monitoring hole JC01, which was located at the front slope and above the artificial scarp, fully reflected the deformation behavior of the front slope before, during, and after the reinforcement construction. Figure 9 shows the horizontal displacements at the three monitoring holes. The largest horizontal displacement, $56 \mathrm{~mm}$, occurred at the front of the deposit slope. The maximum deformation occurred at the top of the inclinometer tube. Monitoring hole JC02, which was located in the potential deformation area, reflected the deformation of the middle slope. Figure 9(b) shows the larger deformation observed (within $28 \mathrm{~m}$ below the inclinometer tube). The largest horizontal displacement of the middle deposit slope was $35 \mathrm{~mm}$. The maximum deformation occurred near the top of the inclinometer tube. Monitoring hole JC03, which was located outside the potential deformation slope, reflected the deformation of the back edge of the slope and provided an early warning as to whether the deformation area of the slope would be enlarged. Figure 7 shows that the maximum horizontal displacement was $28 \mathrm{~mm}$. The maximum deformation occurred near the top of the inclinometer tube.

The measurement results show that the horizontal displacement decreased gradually from the front to the rear of the deposit slope. The artificial scarp significantly reduced the stability of the slope and increased the deformation of the front slope. The horizontal displacement of the middle slope was caused by traction of the front slope. In addition, due to the thrust of the rear slope, the horizontal displacement was distributed to a certain depth. The horizontal displacement of the rear slope was small. The rear slope was pulled by the front and middle slopes. The rear edge of the slope had no obvious thrust effect on the rear slope. The results were confirmed by inspection of the deposit slope surface.

4.4. Deposit Slope Stability Analysis. Given the spatial relationship between the location of the monitoring holes and the section selected for numerical analysis, the monitoring results for hole JC01 and the numerical analysis results were judged to be comparable. Scheme D of Figure 5 shows the horizontal displacements for numerical analysis. Figure 10 shows a comparison of the measured and simulated horizontal displacements at JC01. The measured and simulated horizontal displacements exhibited the same deformation trend. The maximum horizontal displacement occurred at the borehole top, and the minimum displacement occurred at the borehole bottom. The maximum measured and simulated horizontal displacements were $56 \mathrm{~mm}$ and $66 \mathrm{~mm}$, respectively. The measured value was approximately $84.8 \%$ of the simulated value.

As shown in Figure 10, the measured horizontal displacements of the deformation body differed from the numerical results. The reasons are as follows: (1) although monitoring hole JC01 is adjacent to the section considered in the numerical simulation, it is not in the same position, as shown in the plane layout in Figure 1. Both the measured and simulated horizontal displacements exhibit the same deformation trend, which indicates the accuracy of the simulated results to a certain extent. (2) A series of temporary measures were taken to reduce the groundwater level during the construction of the reinforcement system, which effectively improved the stability of the deposit slope. (3) Grouting reinforcement was used in a localized area above the tunnel roof during the construction of the reinforcement system. This further improved the deposit stability above the tunnel roof. The drainage holes and grouting reinforcement mentioned above were not simulated in the numerical model, but they did strengthen the reinforcement system during construction, which explains why the numerically simulated horizontal displacements were larger than the measured ones, as shown in Figure 10. The numerical 


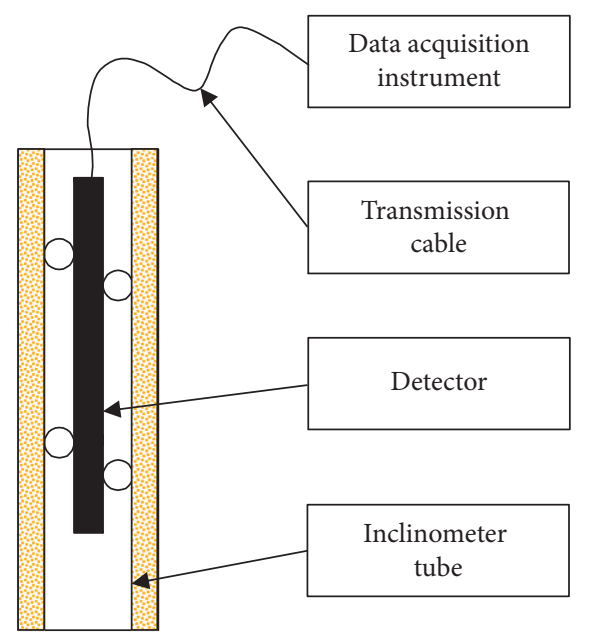

(a)

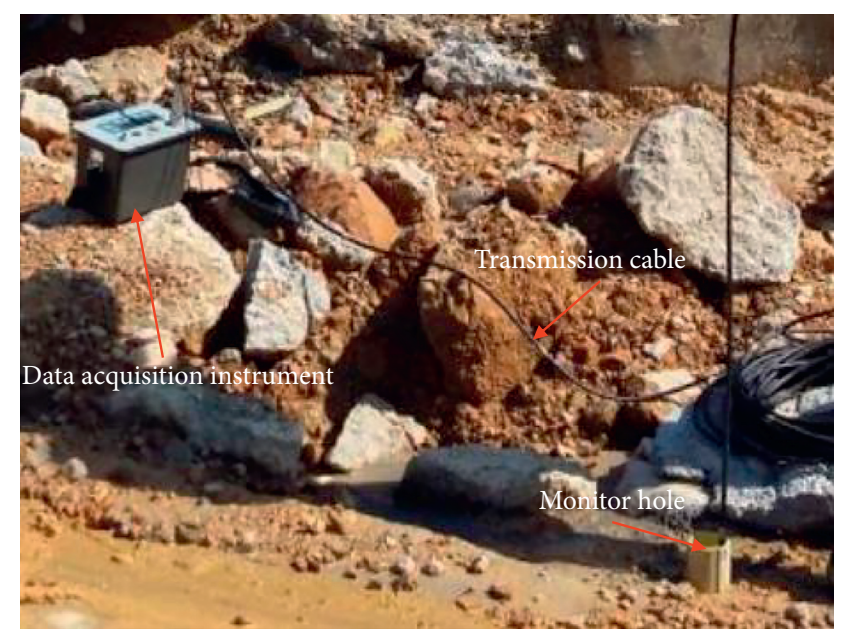

(b)

FIGURE 8: Instrumentation system and photographs of field monitoring.

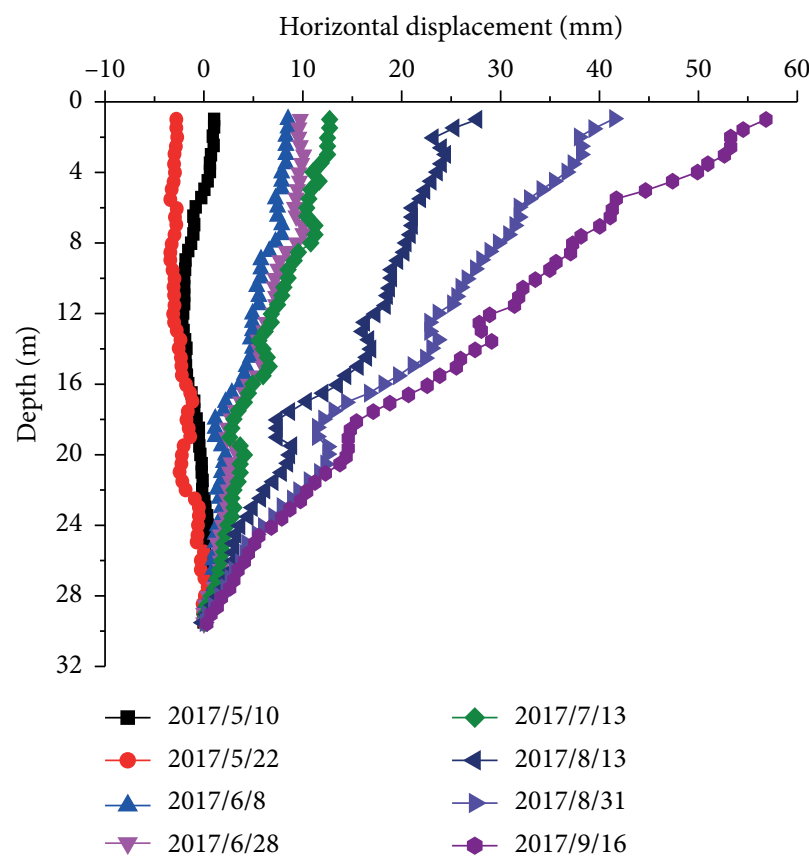

(a)

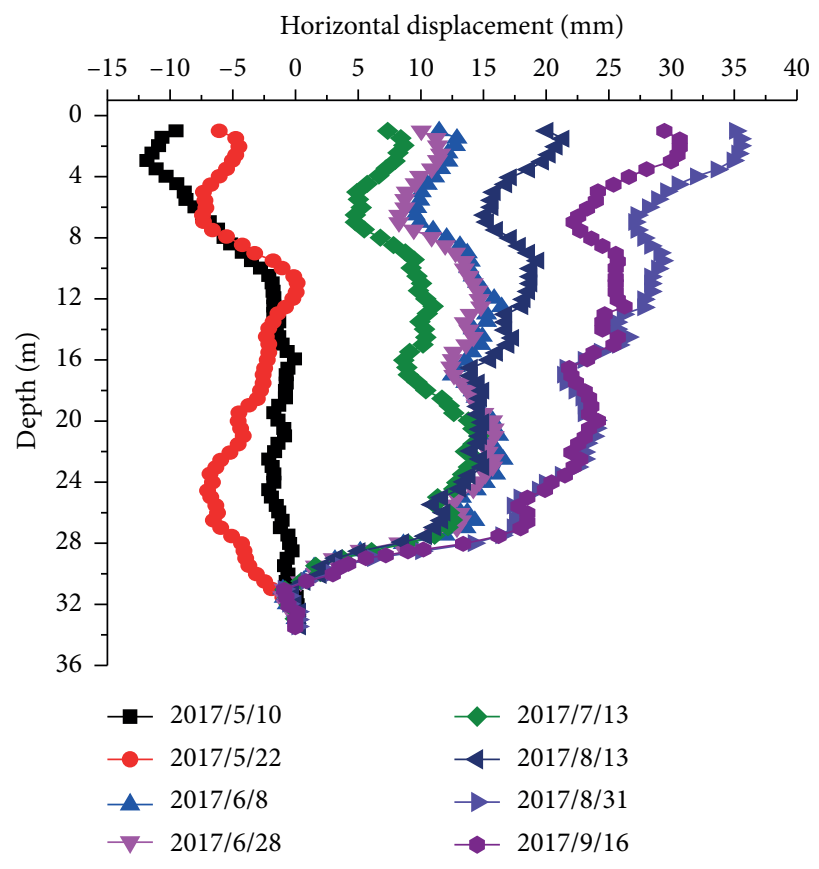

(b)

Figure 9: Continued. 


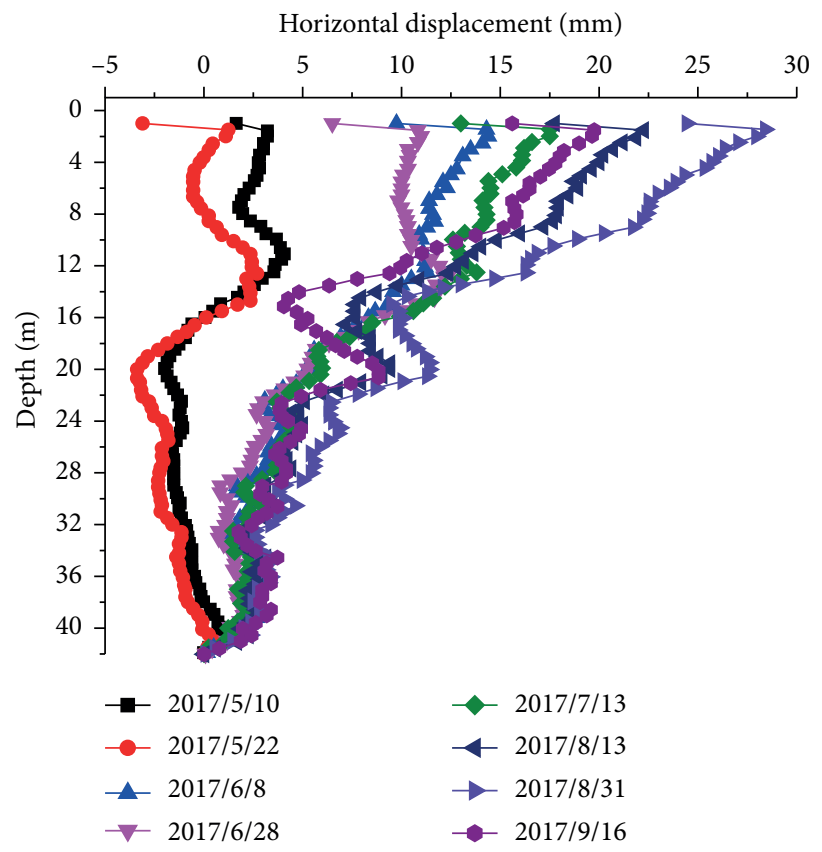

(c)

FIgURE 9: Horizontal displacements at monitoring holes: (a) JC01; (b) JC02; (c) JC03.

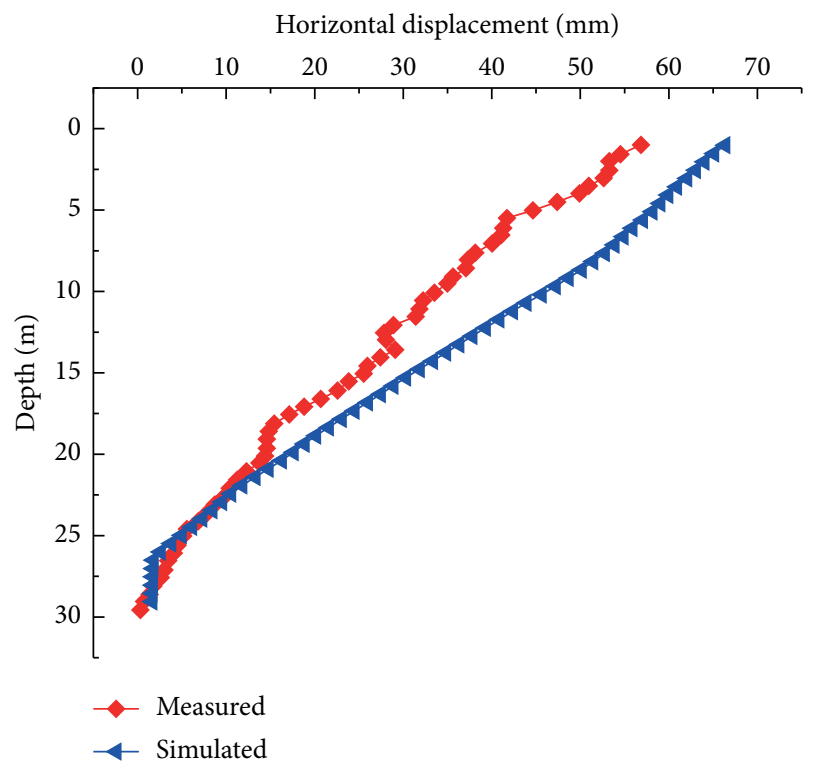

Figure 10: Comparison of measured and numerically predicted horizontal displacements.

simulation results were judged to be consistent with the measured results. The proposed comprehensive reinforcement scheme was therefore judged to be a suitable guide for tunnel slope reinforcement.

Figure 11 shows the displacement increment data for monitoring hole JC01 during the construction of the slope reinforcement and the initial excavation of the tunnel. The deposit slope reinforcement began in the middle of May and lasted for about two months. The tunnel excavation was carried

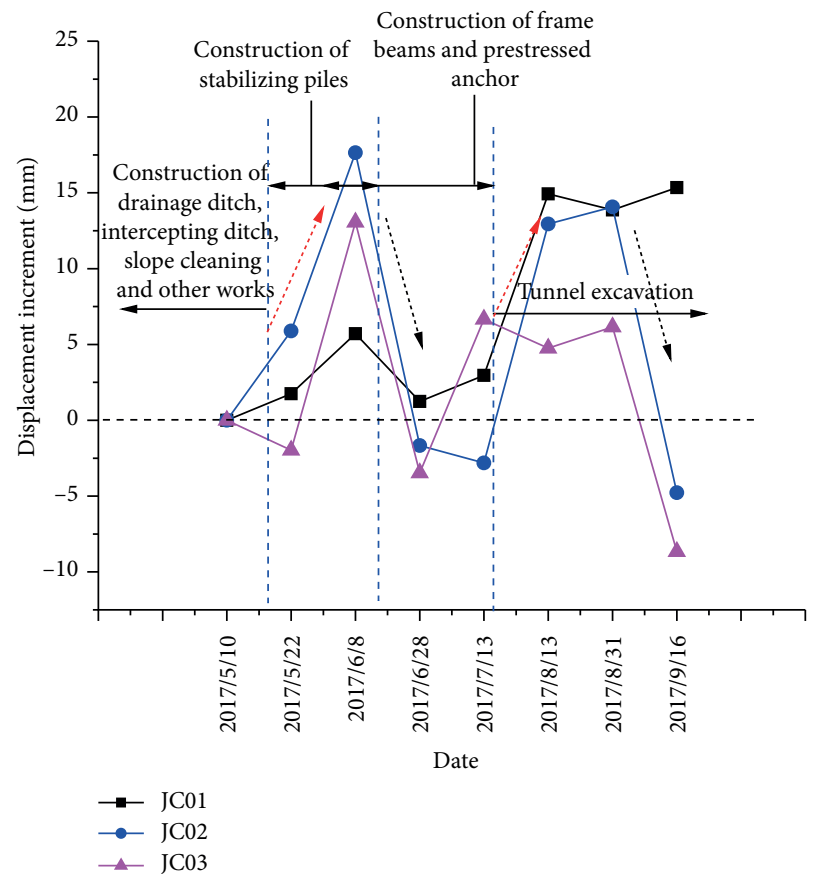

FIGURE 11: Field-monitored displacement increment data for the monitoring holes during slope reinforcement and tunnel excavation.

out after the completion of the reinforcement construction. The monitoring data indicated that the horizontal displacement of the deformation body was found to increase quickly at the beginning of the reinforcement construction and tunnel excavation data. The subsequent rate of horizontal displacement was notably reduced. Before the slope was disturbed, the 
displacement increment was relatively small, less than $5 \mathrm{~mm}$, and the slope was in the ultimate stability state. During the construction of the stabilizing piles, the excavation of the numerous pile holes disturbed the slope and caused a release of stress in the slope. The displacement of the slope tended to increase. However, no obvious deformation of the slope as a whole was observed. During the construction of the prestressed anchor cable frame beam, the displacement of the slope was significantly reduced because of the reinforcement effect of the stabilizing pile and the cessation of disturbance. After the completion of the comprehensive reinforcement construction, the whole reinforced slope was affected by the tunnel excavation. The displacement tended to increase, but the displacement values were all less than $18 \mathrm{~mm}$. The displacement increase tended to be gentle as the tunnel excavation continued to advance. The whole slope was stable. In summary, the analysis results show that the comprehensive reinforcement treatment significantly improved the stability of the deposit slope and ensured the safety of the tunnel construction.

The measured and simulated results together indicate that the failure mode of the deposit was a typical retrogressive landslide type $[36,37]$. The failure process is as follows: the scarp formed by a long-term excavation reduced the slip resistance of the toe of the deposit slope. Significant displacement occurred in front of the deposit. The strength of the rock and soil mass was further reduced by the surface cracks and rainwater infiltration. The front of the deposit slope was in a state of limit equilibrium. If no reinforcement measures are taken, the middle and rear of the deposit slope will be driven to slide. Finally, the whole deposit slope will slide. The slope failure will cause significant property damage and harm to those in the area. As for the retrogressive landslide, the optimal reinforcement site is the lower region of the deposit slope. In this engineering application, the anchors, concrete frame beams, prestressed anchor cables, and front stability piles that were installed at the front of the deposit slope effectively enhanced the safety factor and stability of the deposit slope. The rear stability piles are able to prevent the front deposit from being pushed and the middle and rear of the deposit from being pulled.

\section{Conclusions}

A deposit slope at an exit of the Taihedong tunnel, which is located in the city of Qingyuan in Guangdong Province, China, was analyzed in this study. The deposit slope, with surface cracks, had a scarp formed by a long-term excavation at the toe of the slope and was in a state of limit equilibrium. To determine how to best reinforce the deposit slope, four reinforcement schemes were analyzed based on field measurements and 2D numerical analysis results. The major findings of the study can be summarized as follows:

(1) The maximum horizontal displacement and the minimum safety factor of the deposit slope with the artificial scarp formed by excavation were located at the front of the slope. The horizontal displacements of the middle and rear of the slope decreased gradually, and the safety factor increased steadily.
(2) At the beginning of the reinforcement construction, a large number of excavation piles disturbed the slope and released stress within the slope, resulting in a significant increase in horizontal displacement. The construction of the prestressed anchor cable frame beam reinforcement resulted in less disturbance to the slope. The slope was strengthened by the stability pile, and the horizontal displacement of the slope was notably reduced as a result. The tunnel excavation disturbed the reinforced slope. The horizontal displacement increased notably at first and then became more stable. At all construction stages, the slope as a whole was in a stable state.

(3) The slope stability of this retrogressive-type landslide was improved significantly by the use of prestressed anchor cable frame beam and front stability pile reinforcements, which provided stress compensation for the artificial scarp at the foot of the slope. The antisliding force of the slope was improved. The rear stability piles were found to be effective in preventing the front slope from being pushed and the middle and rear slopes from being pulled and in improving the overall stability of the deposit slope.

\section{Data Availability}

The data used in this study are available from the corresponding author upon request.

\section{Conflicts of Interest}

The authors declare that they have no conflicts of interest.

\section{Acknowledgments}

The authors would like to express their thanks for the financial support provided by the National Natural Science Foundation of China (Grant no. 11872287) and the Foundation of Shaanxi Key Research and Development Program (no. 2019ZDLGY01-10).

\section{References}

[1] G. Barla, F. Antolini, and M. Barla, "Slope stabilization in difficult conditions: the case study of a debris slide in $\mathrm{Nw}$ Italian Alps," Landslides, vol. 10, no. 3, pp. 343-355, 2013.

[2] K. Wu, Z. Shao, S. Qin, W. Wei, and Z. Chu, "A critical review on the performance of yielding supports in squeezing tunnels," Tunnelling and Underground Space Technology, vol. 114, no. 1, 2021.

[3] K. Wu and Z. Shao, "Visco-elastic analysis on the effect of flexible layer on mechanical behavior of tunnels," International Journal of Applied Mechanics, vol. 11, no. 3, Article ID 1950027, 2019.

[4] B. Hu, M. Sharifzadeh, X. T. Feng, W. B. Guo, and R. Talebi, "Roles of key factors on large anisotropic deformations at deep underground excavations," International Journal of Mining Science and Technology, vol. 31, no. 2, 2021.

[5] K. Wu, Z. Shao, and S. Qin, "An analytical design method for ductile support structures in squeezing tunnels," Archives of Civil and Mechanical Engineering, vol. 20, Article ID 91, 2020. 
[6] Y. G. Xue, F. M. Kong, W. M Yang et al., "Main unfavorable geological conditions and engineering geological problems along Sichuan-Tibet railway," Chinese Journal of Rock Mechanics and Engineering, vol. 39, no. 3, pp. 445-468, 2020.

[7] J. P. Huang, C. W. Sun, X. Y. Wu, S. X. Ling, S. Wang, and R. Deng, "Stability assessment of tunnel slopes along the Dujiangyan city to Siguniang mountain railway, China," Bulletin of Engineering Geology and the Environment, vol. 79, 2020.

[8] S. Sun, S. Li, L. Li et al., "Slope stability analysis and protection measures in bridge and tunnel engineering: a practical case study from Southwestern China," Bulletin of Engineering Geology and the Environment, vol. 78, no. 5, pp. 3305-3321, 2019.

[9] K. Wu and Z. Shao, "Study on the effect of flexible layer on support structures of tunnel excavated in viscoelastic rocks," Journal of Engineering Mechanics, vol. 145, no. 10, Article ID 04019077, 2019.

[10] N. Xu, J. Wu, F. Dai, Y. Fan, T. Li, and B. Li, "Comprehensive evaluation of the stability of the left-bank slope at the Baihetan hydropower station in southwest China," Bulletin of Engineering Geology and the Environment, vol. 77, no. 4, pp. 1567-1588, 2018.

[11] D. Q. Song, J. D. Chen, and J. H. Cai, "Deformation monitoring of rock slope with weak bedding structural plane subject to tunnel excavation," Arabian Journal of Geosciences, vol. 11, no. 11, p. 251, 2018.

[12] G. Zhao, Y. Yang, H. Zhang, and G. Zhang, "A case study integrating field measurements and numerical analysis of high-fill slope stabilized with cast-in-place piles in Yunnan, China," Engineering Geology, vol. 253, pp. 160-170, 2019.

[13] Q. B. Zhan, X. J. Sun, C. Li et al., "Stability analysis and reinforcement of a high-steep rock slope with faults: numerical analysis and field monitoring," Advances in Civil Engineering, vol. 2019, p. 8, Article ID 3732982, 2019.

[14] Z. L. Sun, L. W. Kong, and A. G. Guo, "Centrifuge modeling tests on seismic response of lower bedrock deposit slopes before and after reinforced with stabilizing piles," Chinese Journal of Rock Mechanics and Engineering, vol. 36, no. 6, pp. 118-128, 2017.

[15] O. C. Zienkiewicz, C. Humpheson, and R. W. Lewis, "Associated and non-associated visco-plasticity and plasticity in soil mechanics," Géotechnique, vol. 25, no. 4, pp. 671-689, 1975.

[16] M. Pirone and G. Urciuoli, "Analysis of slope-stabilising piles with the shear strength reduction technique," Computers and Geotechnics, vol. 102, pp. 238-251, 2018.

[17] F. Tschuchnigg, H. F. Schweiger, and S. W. Sloan, "Slope stability analysis by means of finite element limit analysis and finite element strength reduction techniques. part I: back analyses of a case history," Computers and Geotechnics, vol. 70, pp. 178-189, 2015.

[18] Z. Chen, Z. Wang, H. Xi et al., "Recent advances in high slope reinforcement in China: case studies," Journal of Rock Mechanics and Geotechnical Engineering, vol. 8, no. 6, pp. 775788, 2016.

[19] K. Wu, Z. Shao, S. Qin, and B. Li, "Determination of deformation mechanism and countermeasures in silty clay tunnel," Journal of Performance of Constructed Facilities, vol. 34, no. 1, Article ID 04019095, 2020.

[20] Y. Huang, X. Xu, J. J. Liu, Huang, and W. W. Mao, "Centrifuge modeling of seismic response and failure mode of a slope reinforced by a pile-anchor structure," Soil Dynamics and Earthquake Engineering, vol. 131, pp. 1-11, 2020.
[21] K. Wu, Z. Shao, S. Qin, N. Zhao, and H. Hu, "Analyticalbased assessment of effect of highly deformable elements on tunnel lining within viscoelastic rocks," International Journal of Applied Mechanics, vol. 12, no. 3, Article ID 2050030, 2020.

[22] W. C. Cheng, G. Li, N. N. Liu, J. Xu, and S. Horpibulsuk, "Recent massive incidents for subway construction in soft alluvial deposits of Taiwan: a review," Tunnelling and Underground Space Technology, vol. 96, Article ID 103178, 2020.

[23] H. Q. Chen, R. Q. Huang, and F. Lin, "Study on the spatial engineering effect of large accumulation slope," Chinese Journal of Geotechnical Engineering, vol. 27, no. 3, pp. 323-328, 2005.

[24] Z. Sun, L. Kong, A. Guo, and M. Alam, "Centrifuge model test and numerical interpretation of seismic responses of a partially submerged deposit slope," Journal of Rock Mechanics and Geotechnical Engineering, vol. 12, no. 2, pp. 381-394, 2020.

[25] Y.-S. Song, W.-P. Hong, and K.-S. Woo, "Behavior and analysis of stabilizing piles installed in a cut slope during heavy rainfall," Engineering Geology, vol. 129-130, pp. 56-67, 2012.

[26] G. Bicocchi, V. Tofani, M. D’Ambrosio et al., “Geotechnical and hydrological characterization of hillslope deposits for regional landslide prediction modeling," Bulletin of Engineering Geology and the Environment, vol. 78, no. 7, pp. 4875-4891, 2019.

[27] V. Gupta, R. K. Bhasin, A. M. Kaynia et al., "Finite element analysis of failed slope by shear strength reduction technique: a case study for Surabhi Resort Landslide, Mussoorie township, Garhwal Himalaya," Geomatics, Natural Hazards and Risk, vol. 7, no. 5, pp. 1677-1690, 2016.

[28] I. Jamir, V. Gupta, V. Kumar, G. T. Thong, and G. T. Thong, "Evaluation of potential surface instability using finite element method in Kharsali Village, Yamuna Valley, Northwest Himalaya," Journal of Mountain Science, vol. 14, no. 8, pp. 1666-1676, 2017.

[29] D. P. Kanungo, A. Pain, and S. Sharma, "Finite element modeling approach to assess the stability of debris and rock slopes: a case study from the Indian Himalayas," Natural Hazards, vol. 69, no. 1, pp. 1-24, 2013.

[30] P. Shilpa, M. K. Amir, K. B. Rajinder, and D. K. Paul, "Earthquake stability analysis of rock slopes: a case study," Rock Mechanics and Rock Engineering, vol. 45, pp. 205-215, 2012.

[31] T. Matsui and K. C. San, "Finite element stability analysis method for reinforced slope cutting," in Proceedings of the International Geotechnical Symposium on Theory and Practice of Earth Reinforcement, pp. 317-322, Fukuoka, Japan, October 1988.

[32] T. Matsui and K.-C. San, "Finite element slope stability analysis by shear strength reduction technique," Soils and Foundations, vol. 32, no. 1, pp. 59-70, 1992.

[33] T. K. Nian, G. Q. Chen, S. S. Wan, and M. T. Luan, "Nonconvergence criterion on slope stability FE analysis by strength reduction method," Journal of Convergence Information Technology, vol. 6, no. 5, pp. 78-88, 2011.

[34] D. V. Griffiths and P. A. Lane, "Slope stability analysis by finite elements,” Géotechnique, vol. 49, no. 3, pp. 387-403, 1999.

[35] G. Tiwari and G. M. Latha, "Design of rock slope reinforcement: an himalayan case study," Rock Mechanics and Rock Engineering, vol. 49, no. 6, pp. 2075-2097, 2016. 
[36] J. W. Zhang, Y. Zou, and Y. L. Li, "Failure mechanism and stability analysis of big multi-layer deposit," Chinese Journal of Rock Mechanics and Engineering, vol. 35, no. 12, pp. 24792489, 2016.

[37] G. H. Yang, Z. H. Zhong, Y. C. Zhang, and E. Q. Wang, "Dentification of landslide type and determination of optimal reinforcement site based on stress field and displacement field," Chinese Journal of Rock Mechanics and Engineering, vol. 31, no. 9, pp. 1879-1887, 2016. 